\title{
Analytical Modelling of Ion-Exchange Process during Removal of Copper Cations from Aqueous Solutions using Clinoptilolite
}

\author{
John Kabuba* and Etienne Ngoy
}

\begin{abstract}
An analytical method based on the shrinking core mechanism (SCM) is suggested for the modelling of the ion-exchange process during the removal of copper cations from aqueous solutions using clinoptilolite. The surface coverage of the clinoptilolite by the adsorbed cations is simulated as a shrinking of particle of irregular geometry during a non-catalytic heterogeneous solid-fluid reaction. The mathematical fitting of the relative experimental data allows one to show that the ion-exchange process during the removal of copper cations from aqueous solutions can also be simulated as a shrinking-core mechanism. The simulation is shown to be $95 \%$ accurate for the present case. The method can be used for a multivariable modelling approach.
\end{abstract}

Keywords-Analytical modelling, clinoptilolite, copper aqueous solution, ion-exchange.

\section{INTRODUCTION}

Ion-exchange process is a reversible chemical reaction where an ion from solution is exchanged for a similarly changed ion attached to an immobile solid material [1]. This process is one of the most commonly used techniques for the removal of heavy metals from contaminated water. In this process, the solid material with ion-exchange capability is contacted with an electrolyte solution and exchangeable ions from the solid material pass into solution while targeted solution ions are fixed on the solid material. Ion-exchange materials are classified as synthetic as well as natural solid material. Synthetic ion exchangers are resins prepared from organic polymers to which ionisable groups have been added. These include, for instance, strong base quaternary ammonium groups or weak base ammonium groups for anion exchangers, and carboxylic acid or sulphonic acid groups for cations. In the polymer structure these groups are balanced by mobile counterions that provide exchangeable ions. The natural ion exchangers are mainly silicates as well as carbonated rich minerals such as calcite, dolomite, and magnetite. Zeolites are the typical form of natural silicate and have attracted considerable interest as they offer several advantages, including low cost, high selectivity toward heavy metals, compatibility to environment, good resistance to

Manuscript received September 4, 2017.

*J. Kabuba is with the Department of Chemical Engineering, Vaal University of Technology, Vanderbijlpark, Private Bag X021.

E. Ngoy is with the Department of Chemical Engineering, Vaal University of Technology, Vanderbijlpark, Private Bag X021. thermal decomposition and ionizing radiations [2]. Zeolites are aluminosilicates that have a framework structure with enclosed cavities and tunnels which are occupied by freely moving hydrated cations that make ion exchange possible [3]. Clinoptilolite is the most abundant and cosmopolite zeolites, clinoptilolite has been widely exploited for its ion-exchange capabilities since it can easily exchange its interstitial sodium for external cations in solution [3]. The present analysis focuses on clinoptilolite, a naturally occurring and abundant South African zeolite, as a low-cost adsorbent for the removal of $\mathrm{Cu}^{2+}$ in mine-water effluents.

Ion-exchange operations are generally conducted in fixed-bed absorbers. Adsorption columns offer the capability to handle large quantities of feed in a continuous process and cyclically between two parallel adsorption columns to allow for regeneration time. The batch technique is also used where powdered ion-exchange material is added to the solution in a tank using mechanical or pneumatic agitation. The sizing of an adsorption column consists of optimizing several operating parameters such as the hydrodynamic velocity, the bed area, the bed length for a given cycle time, the breakthrough curves or the concentration profile over the bed length. The scaling up is generally obtained from experimental laboratory or pilot-plant data. This procedure is lengthy and costly. Accurate modelling and simulation techniques have been reported; however, they generally require lengthy and complex computations [4], [5], [6]. In terms of modelling and simulation of the adsorption column operations, two main trends have been surveyed according to Othman et al. [5]. These include the heterogeneous approach where the system is viewed as a two-phase structure, and the homogeneous approach where the adsorption system is taken as a single-phase structure indirectly accounting for a static phase [5], [6]. In both approaches, the modelling is based on mass-balance equations.

Another trend in modelling of ion exchange focuses on kinetics and equilibrium studies of the reaction between two phases. Empirical as well as mechanistic methods are used mainly to relate adsorbate concentration to the adsorption time under fixed operating conditions [7]. The empirical isotherms of Langmuir and Freundlich along with their evolved versions such as the competitive Langmuir equation and the multisite Langmuir isotherm have been widely used for decades [7]. Reported studies on ion-exchange reactions show that the 
reaction mechanism involves several sub-processes such as surface diffusion, pore diffusion, diffusion through the fluid film, and other competing processes such as surface complexation [1], [7]. The process is dependent on a number of parameters including $\mathrm{pH}$, dosage and initial concentration [1], [7], [8]. While numerous studies have been conducted and findings reported on the effect of the above parameters, a literature review revealed no published reports on the modelling of the ion-exchange process explicitly involving the factor effect. This analysis is part of a study that was undertaken in order to develop a multivariable model of the ion-exchange process applied to the removal of copper ions from aqueous solutions. The paper presents an application of the shrinking-core model (SCM) of heterogeneous solid-fluid reaction to the simulation of the ion-exchange process during the removal of copper cations from aqueous solutions. The mathematical formulation of the SCM presented by Levenspiel [9] offers possibilities to explicitly include the effects of process parameters.

\section{REACTION PATTERN}

In this development, the reacting system is depicted as a non-catalytic solid-fluid heterogeneous mixture with two components. The process mechanism involves a diffusion step and the chemical reaction at the component interface. The transformation of the solid particle involves a modification of the surface configuration through the coverage by adsorbed cations. The geometry of this transformation pattern is associated with shrinkage of solid grains of irregular geometry. In the mathematical formulation of the SCM developed by Levenspiel the solid grains are assumed to have regular geometry which leads to linear variation in time. According to the method used by Levenspiel, irregular shapes should generate non-linear variations in time. Therefore, in the present case, Levenspiel formulas are used with a non-linear time exponent and effects of process parameters.

\section{EXPERIMENTAL}

Data were obtained from a batch process experiment where 4 $\mathrm{g}$ of clinoptilolite were mixed with $20 \mathrm{~mL}$ of a $\mathrm{Cu}^{2+}$ solution in a $30-\mathrm{mL}$ burette. Experiments were conducted at room temperature and the $\mathrm{pH}$ of the mixture was adjusted to $\mathrm{pH} 6.5$ using $\mathrm{NaOH}$. The initial concentration of the adsorbate solution was $\mathrm{C}=474.5 \mathrm{mg} / \mathrm{L}$. After extraction, loaded clinoptilolite was subjected to an elution process using sulphuric acid at $0.2 \mathrm{M}$. The conventional stirred tank (batch reactor) method was used to investigate the kinetic performance of clinoptilolite in removing $\mathrm{Co}^{2+}$ from aqueous solution. The batch reactor consists of a glass container in which the clinoptilolite-solution system was stirred at $900 \mathrm{rpm}$ at room temperature. The behaviors of clinoptilolite in distillated water was studied with contact time for $90 \mathrm{~min}$. Quantitative analysis of eluent solution was done by atomic absorption spectrometry (AAS). Results of the fraction of clinoptilolite surface coverage as a function of time are presented in Fig. 1.

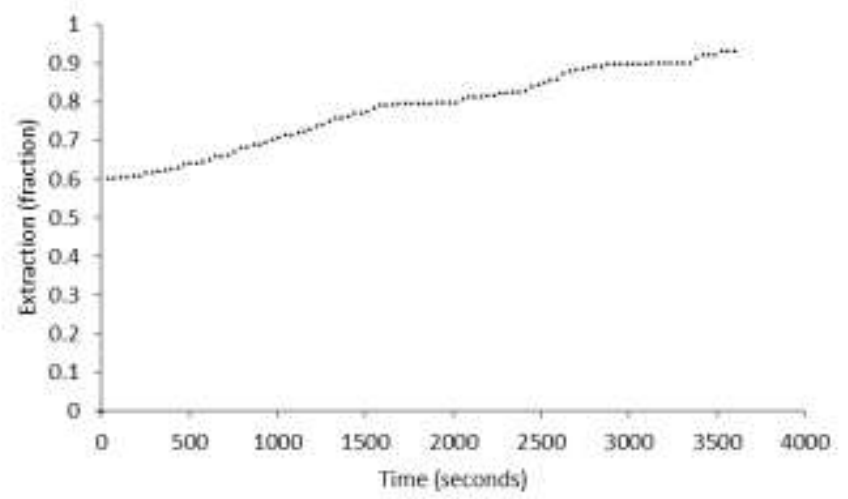

Fig. 1. Clinoptilolite surface coverage obtained by elution

For shrinking core model, reaction proceeds at a narrow interface which moves into the solid particle. Reactant is completely converted as the reaction interface passes at any time. There exists an unreacted core of material which shrinks in site during reaction. All steps have to be in consequence to proceed. The overall process slowest steps are rate-limiting. The limiting assumption for further mathematical descriptions are: chemical reaction is elementar and one direction, particle has spherical shape.

Specific equations are used for calculating the corresponding coefficient for each rate-controlling process (diffusion thru the film- diffusion thru internal layer- chemical reaction). In all equation, the fractional conversion $\mathrm{X}$ (the solid-phase concentration) is used: The diffusion thru the film control step is presented by Eq. (1) [8]:

$$
X=\frac{3 a k_{f}}{q_{\max } \rho_{p} r} \int_{0}^{b} c d t
$$

where $\mathrm{k}_{\mathrm{f}}$ is the mass transfer coefficient in the film surrounding the particle $(\mathrm{mm} / \mathrm{min}), a=1$ represents the stoichiometric coefficient, $\mathrm{c}$ the fluid phase bulk concentration of copper $(\mathrm{mg} / \mathrm{L}), \mathrm{r}$ the radius of the particle $(\mathrm{mm}), \mathrm{q}_{\max }$ the maximum exchange capacity $(\mathrm{mg} / \mathrm{g}), \rho_{\mathrm{p}}$ is the particle density $(\mathrm{g} / \mathrm{mL})$. The solid diffusion control step is described by Eq. (2) [8]:

$$
1-3(1-X)^{\frac{2}{3}}+2(1-X)=\frac{6 b D}{\rho r^{2}} \int_{0}^{t} c d t
$$

and $\rho=q_{\max } \rho_{p}$

where $\rho$ is the molar density in the solid phase, D the effective diffusion coefficient of copper in clinoptilolite $\left(\mathrm{mm}^{2} / \mathrm{min}\right)$.

The chemical reaction kinetic control step is described by Eq. (4):

$$
1-(1-X)^{\frac{1}{3}}=\frac{b k}{\rho r} \int_{0}^{t} c d t
$$

where $\mathrm{k}$ is the first-order rate constant $(\mathrm{mm} / \mathrm{min})$.

\section{RESULTS AND DISCUSSION}

\section{A. Fitting of Experimental Data by SCM}

The experimental data were fitted with SCM equations using 
linear time variation. In addition, the progression conversion model and the Avrami equation were also tried in fitting the experimental data. From the following results:

1. Model mechanism: SCM, kinetics controlled by diffusion through the liquid (film and chemical reaction for flat plate grain),

$f(x)=1$

Coefficient of linear correlation $\mathbf{R}^{2}: t=0$.

2. Model mechanism: SCM, kinetics controlled by diffusion through the solid ash layer (spherical particle),

$f(x)=1-3(1-X)^{\frac{2}{3}}+2(1-X)$

Coefficient of linear correlation $\mathbf{R}^{2}: \mathrm{t}=0.772$;

$\mathrm{t}^{1.25}=0.581 ; \mathrm{t}^{5}=0.363 ; \mathrm{t}^{1.75}=0.130 ; \mathrm{t}^{2}=0$.

3. Model mechanism: Kinetics controlled by the chemical reaction (spherical particle),

$$
f(x)=1-(1-X)^{\frac{1}{3}}
$$

Coefficient of linear correlation $\mathbf{R}^{2}: t=0.3010$

4. Model mechanism: Kinetics controlled by diffusion through the solid ash layer (flat plate grain),

$$
f(x)=X^{2}
$$

Coefficient of linear correlation $\mathbf{R}^{2}: t=0$.

5. Model mechanism: Kinetics controlled by diffusion through the solid ash layer (cylindrical particle),

$f(x)=X-(1-X) \ln (1-X)$

Coefficient of linear correlation $\mathbf{R}^{2}: t=0$

6. Model mechanism: Kinetics controlled by the chemical reaction (cylindrical particle)

$$
f(x)=1-(1-X)^{\frac{1}{2}}
$$

Coefficient of linear correlation $\mathbf{R}^{2}: t=0$

7. Model mechanism: Mixed kinetics determining steps (diffusion through solid layer and mass transfer through liquid film)

$$
f(x)=\frac{1}{3} \ln (1-X)-\left[1-(1-X)^{-\frac{1}{3}}\right]
$$

Coefficient of linear correlation $\mathbf{R}^{\mathbf{2}}: \mathrm{t}=0.890$;

$$
\mathrm{t}^{1.25}=0.932 ; \mathrm{t}^{5}=0.943 ; \mathrm{t}^{1.75}=0.936 ; \mathrm{t}^{2}=00915 \text {. }
$$

8. Model mechanism: PCM pseudo-second-order

$$
f(x)=\frac{X}{1-X}
$$

Coefficient of linear correlation $\mathbf{R}^{\mathbf{2}}: \mathrm{t}=0.860$;

$\mathrm{t}^{1.25}=0.800 ; \mathrm{t}^{5}=0.913 ; \mathrm{t}^{1.75}=0.909 ; \mathrm{t}^{2}=0.892$.

9. Model mechanism: Avrami equation

$$
f(x)=\frac{X}{1-X}
$$

Coefficient of linear correlation $\mathbf{R}^{2}: t=0.50$.

It can be seen that none of the models (Eq. 5-13) with linear time variations provided a satisfactory fitting. Therefore, the best fit was selected and improved by gradual variation of the time exponent. It could be concluded that the ion-exchange process during the removal of copper cations from aqueous solutions can also be simulated as a shrinking-core mechanism. The mathematical formulation is that of kinetics determined by the diffusion through the product layer and the liquid film as follows:

$\frac{1}{3} \ln (1-X)-\left[1-(1-X)^{-\frac{1}{3}}\right]=k t^{1.5}$

According to the development of Levenspiel formulation, the constant in Eq. (14) takes account of the effect of process parameters such as concentration of adsorbate in the solution, operating temperature, $\mathrm{pH}$, diffusion and others. This formulation can therefore provide a basis for analytical modelling of the ion-exchange process during the removal of copper cations from aqueous solutions, using a multivariable approach. The constant was experimentally determined to be for the present case.

\section{B. Effect of $p H$}

Since $\mathrm{pH}$ has a major influence on the process, initial studies were done to investigate the interaction between the clinoptilolite and solution that might lead to an increase/decrease in the $\mathrm{H}^{+}$concentration. The clinoptilolite-solution system was studied for three consecutive contact cycles of $90 \mathrm{~min}$. During each cycle, the $\mathrm{pH}$ values were monitored and the results are presented in Fig. 2.

The results show a decrease of $\mathrm{pH}$ during the first cycle, followed by a steady-state plateau reached after $40 \mathrm{~min}$. The second and third cycle, $\mathrm{pH}$ decreases in the first $20 \mathrm{~min}$. The data show that a pre-conditioning step is necessary, for getting reproducible results, due to the interaction of the clinoptilolite with solution, either because of a $\mathrm{Na}^{+} / \mathrm{H}^{+}$exchange equilibrium but more likely because of a reversible water swelling in the clinoptilolite on the sited located in the micropores.

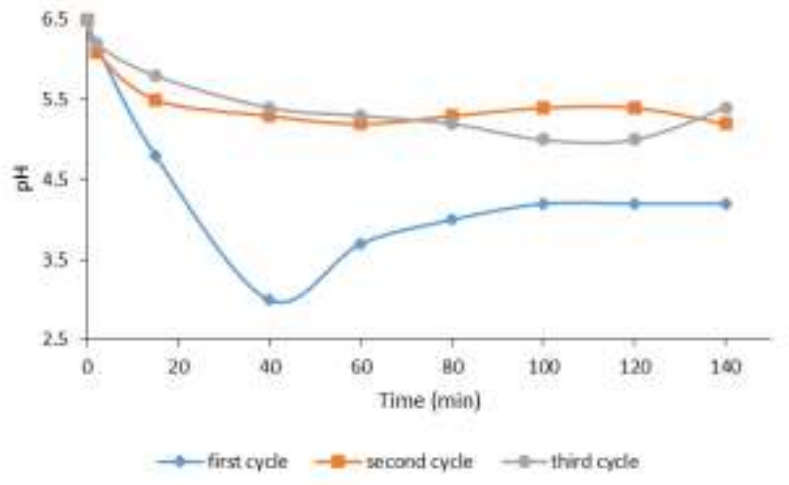

Fig. 2. pH evolution in the clinoptilolite-solution system

\section{Effect of Dosage}

The influence of the clinoptilolite dosage was studies using a solution of $474.5 \mathrm{mg} / \mathrm{L}$ and different amount of $0.5,1.0,2.0$ and $4.0 \mathrm{~g}$. The removal efficiency results presented in Fig. 3 show that there is increase with the clinoptilolite dosage up to $2 \mathrm{~g} / 100$ $\mathrm{mL}$ solution. The results can be anticipated because a larger amount of clinoptilolite provides an increased number of 
sorption sites for fixed initial concentration as long as the process is under kinetic control. Increasing the amount of substrate above $2 \mathrm{~g}$ brings no significant improvement (the process being under diffusional control) therefore, the optimum clinoptilolite dosage in further sorption experiments was set as $2.0 \mathrm{~g}$.

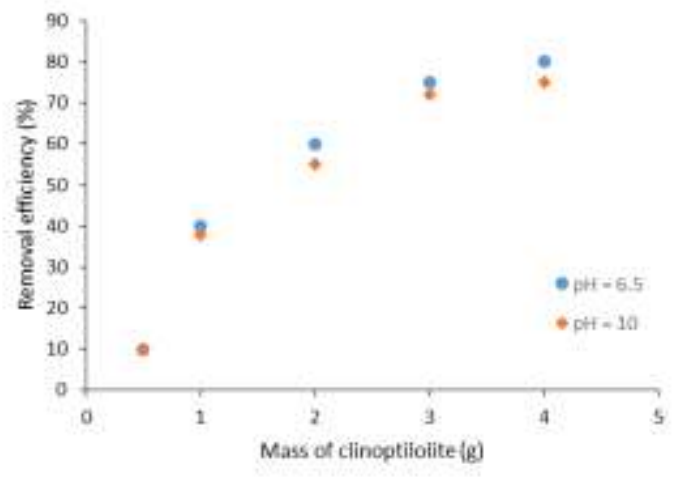

Fig. 3. Effect of clinoptilolite on the removal efficiency

\section{Effect of Initial Concentration}

A fixed amount of $2 \mathrm{~g}$ clinoptilolite was used with $100 \mathrm{ml}$ of solution at different concentration. The results presented in Fig. 4 show higher removal efficiency for $\mathrm{pH} 6.5$ than $\mathrm{pH} 10$ on the entire concentration range. The results obtained in the experiments at $\mathrm{pH} 10$ are consistent with lower amount of cation, involved in ion-exchange, showing lower efficiency at low solution concentration, when the cation diffusion toward the substrate is limiting step in the mechanism. Significant higher salt concentrations lead again to lower (and almost constant) efficiencies, proving also a possible interaction of the substrate with $\mathrm{Na}^{+}$from $\mathrm{NaOH}$ added for $\mathrm{pH}$ control.

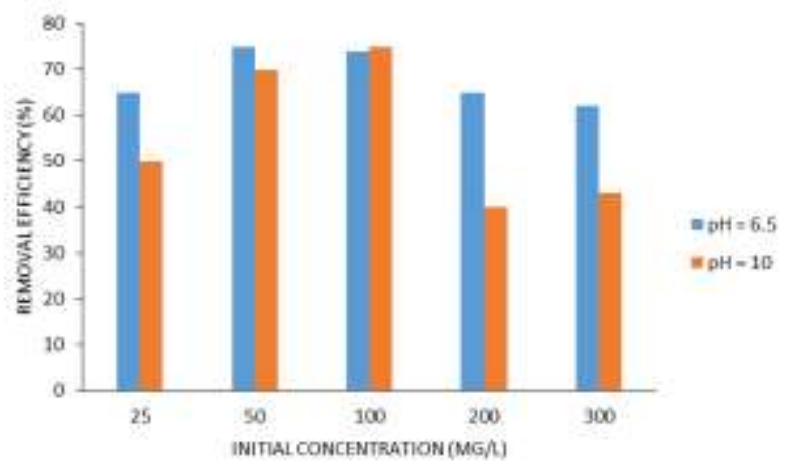

Fig. 4. Effect of initial concentration

\section{E. Kinetic Study}

For this study, $2.0 \mathrm{~g}$ of clinoptilolite was added in $100 \mathrm{ml}$ of $474.5 \mathrm{mg} / \mathrm{l}$ of solution. Considering the results obtained in equilibrium study, the system clinoptilolite -solution at $\mathrm{pH} 6.5$ was investigated. $0.5 \mathrm{ml}$ were taken at $10 \mathrm{~min}$ and the momentary concentrations were evaluated. On these data, the shrinking core model was applied. The Eq. (14) was plotted against $X_{B}$. It can be seen from Fig. 5 that during the first 20 min all three processes are running in parallel, followed by a steady-state, reached by all three processes at the same time. Considering the overall mechanism, the most likely sequences is: liquid diffusion-chemical reaction-solid diffusion and the results show that the contribution of solid diffusion is very low, but not zero, indicating that beside ion exchange also regular adsorption can occur. It can be concluded that the chemical reaction is the fastest step, limited by film and/or solid diffusion.

(a)

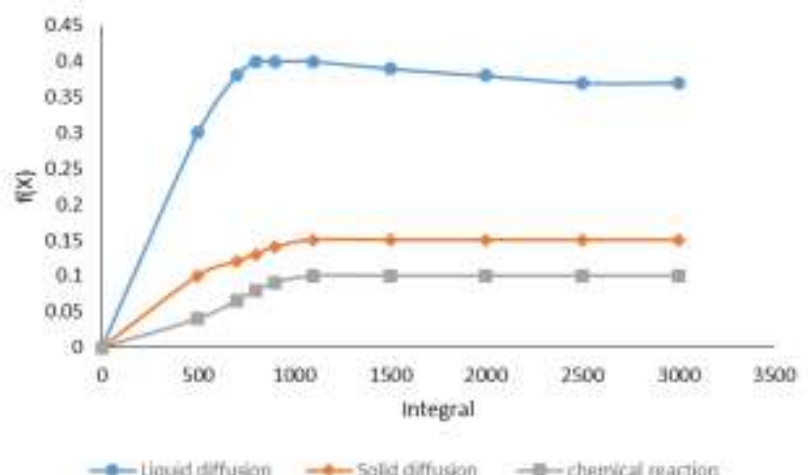

(b)

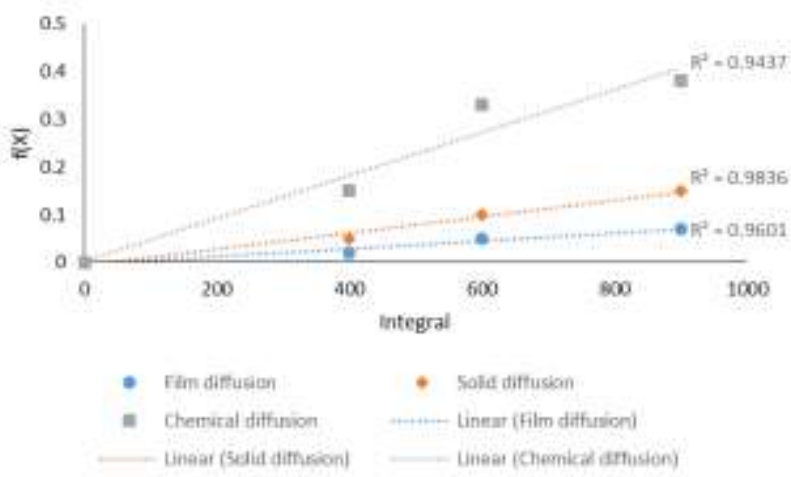

Fig. 5. (a)Shrinking core model for clinoptilolite-solution system and (b) Linearization

\section{MODEL ACCURACY}

The accuracy of the simulation was assessed by comparing experimental results to simulated values of the extraction. This was done through the function $f(x)$ that represents a process mechanism with kinetics determined by diffusion through the product layer and the fluid film:

$f(x)=\frac{1}{3} \ln (1-X)-\left[1-(1-X)^{-\frac{1}{3}}\right]$

Now let $f_{e}(x)$ represent experimental values and $f_{s}(x)$ simulated values of $f(x)$. Experimental values of $f(x)$ were calculated by using experimental values of $x$. The simulated values were obtained according to Eq. (15) by calculating $2.3 \mathrm{t}^{1.5}$. Then the accuracy of the simulation was evaluated by the resultant errors over the total extraction duration represented by $\Delta t$. To this end the respective integral sums of the experimental values and those of the simulation values were calculated as $\sum_{\Delta t} f_{e}(x)$ and $\sum_{\Delta t} f_{s}(x)$. The integrated and simulated values were then graphically depicted and are represented in Fig. 6. 


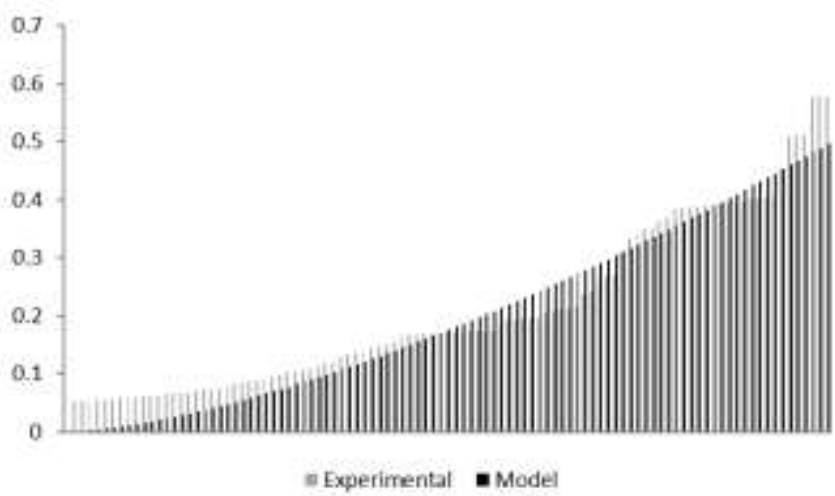

Fig. 6: Comparing experimental and simulated values of $f(x)$

The resultant error is represented by the difference between the two surfaces in Fig. 6 and was subsequently expressed as a percentage of experimental values as follows:

$$
\text { error }_{\Delta t}=\frac{\sum_{\Delta t}\left[f_{e}(x)-f_{s}(x)\right]}{\sum_{\Delta t} f_{e}(x)}
$$

Based in Eq. (16), the resultant error over the total extraction time was found to be:

$$
\text { error }_{\Delta t}=5 \%
$$

Therefore, it could be concluded from Eq. (17) that the simulation was $95 \%$ accurate.

\section{CONCLUSION}

Copper cations were extracted from an aqueous solution by an ion-exchange process using clinoptilolite. The resulting experimental data were mathematically fitted using SCM. It is shown that the ion-exchange process during the removal of copper cations from aqueous solutions can also be simulated as a shrinking-core mechanism. The mathematical formulation is that of kinetics determined by the diffusion through the product layer and the liquid film. The resulting error of simulation over the total extraction time was also calculated and was found to be only $5 \%$, showing that the simulation is $95 \%$ accurate. The shrinking-core model can therefore provide a basis for analytical modelling of the ion-exchange process during the removal of copper cations from aqueous solutions, using a multivariable approach.

\section{ACKNOWLEDGMENT}

The authors gratefully acknowledge the support received from the Vaal University of Technology.

\section{REFERENCES}

[1] D.W. Nyembe, B.B. Mamba and A.F. Mulaba-Bafubiandi. "Adsorption mechanism of $\mathrm{Co}^{2+}$ and $\mathrm{Cu}^{2+}$ from aqueous solutions using natural clinoptilolite: equilibrium and kinetics studies". J. Appl. Sci., vol. 10, pp. 599-610, 2010 https://doi.org/10.3923/jas.2010.599.610

[2] A. Amankwah and J. Kabuba. "Comparison of Neural Networks and Kalman Filter for the Modeling of Ion-exchange Process". Life Sci. J., vol. 10, pp. 1012-1015.
[3] J. Kabuba, A. Mulaba-Bafubiandi and K. Battle. "Neural Network Technique for Modelling of $\mathrm{Cu}$ (II) Removal from Aqueous Solution by Clinoptilolite". Arab. J. Sci. Eng., vol. 39, pp. 6793-6803. https://doi.org/10.1007/s13369-014-1277-2

[4] W.L. McCabe, J.C. Smith and P. Harriott. "Unit Operation of Chemical Engineering". Boston: McGraw-Hill, pp. 836-881, 2005.

[5] H. O. Sameh, M. S. Mahmoud, M. Demerdash and E. El-Anadouli Bahgat E. "Mathematical model: Retention of beryllium on flow-through fixed bed reactor of Amb-IR-120". Chem. Eng. J., vol. 156. pp. 157-164, 2010 https://doi.org/10.1016/j.cej.2009.09.018.

[6] M. Demerdash,M.S. Saleh Mahmoud., M. Shabaan , H.O. Sameh and B.E. El-Anadouli. "Experimental validation for a mathematical model describing beryllium retention on flow-through fixed bed reactor of Amb-IR-120”. Hydrometall., vol. 108, pp.136-142, 2011. https://doi.org/10.1016/j.hydromet.2011.03.009

[7] B.H. Bradl. "Adsorption of heavy metal ions on soils and soils constituents". J. Colloid Interface Sci., vol. 277, pp. 1-18, 2001. https://doi.org/10.1016/j.jcis.2004.04.005

[8] M. Sica, A. Duta, C. Teodosiu and C. Draghici. "Thermodynamic and Kinetic study on ammonium removal from a synthetic water solution using ion exchange resin". Clean Techn. Environ. Policy, vol. 16, pp. 351-356, 2014. https://doi.org/10.1007/s10098-013-0625-3

[9] O. Levenspiel. Chemical Reaction Engineering, 3rd edition. New York: John Wiley \& Sons, 1999. 